\title{
REVIEW
}

\section{Fractional Flow Reserve in Acute Myocardial Infarction: A Guide for Non-Culprit Lesions?}

\author{
Dmitriy S. Sulimov · Mohamed Abdel-Wahab $\cdot$ Gert Richardt
}

To view enhanced content go to www.cardiologytherapy-open.com Received: February 18, 2015 / Published online: June 9, 2015

(C) The Author(s) 2015. This article is published with open access at Springerlink.com

\section{ABSTRACT}

In patients presenting with ST-segment elevation myocardial infarction (STEMI) and multi-vessel disease (MVD), the optimal therapy for non-culprit lesions is still a matter of debate. While guidelines discourage a concomitant treatment of infarct- and non-infarct-related arteries, recent studies document advantages of a complete (preventive) revascularization during primary percutaneous coronary intervention. Such an approach, however, may result in overtreatment, because angiography does not provide robust information about the functional severity of MVD. Fractional flow reserve (FFR) measurements can be a valuable guide for non-culprit lesions in acute myocardial infarction, but so far, only the reliability and safety of FFR measurements have been established in this setting. The

Electronic supplementary material The online version of this article (doi:10.1007/s40119-015-0040-4) contains supplementary material, which is available to authorized users.

D. S. Sulimov · M. Abdel-Wahab · G. Richardt ( $₫)$ Heart Center, Segeberger Kliniken $\mathrm{GmbH}$, Academic Teaching Hospital of the Universities of Kiel, Lübeck, and Hamburg, Bad Segeberg, Germany e-mail: gert.richardt@segebergerkliniken.de clinical implications of an FFR-guided treatment strategy in STEMI patients with MVD are currently being tested in a large randomized trial.

Keywords: Coronary artery disease; Fractional flow reserve; Myocardial infarction

\section{THE DILEMMA OF NON-CULPRIT LESIONS AND PRIMARY PERCUTANEOUS CORONARY INTERVENTION}

Early and successful recanalization of the infarct-related artery is the principal treatment goal in patients presenting with acute STsegment elevation myocardial infarction (STEMI) [1, 2]. In about half of the STEMI patients, coronary angiography reveals multivessel disease (MVD) with at least one angiographically significant lesion in a noninfarct-related artery [1-4]. STEMI patients with MVD have been identified as a high-risk cohort with lower reperfusion success and poorer longterm outcome since the early days of primary percutaneous coronary intervention (PCI) [5], 
but only recently interventional cardiologists have recognized the optimal management of non-culprit lesions as one of the last open questions in modern infarct therapy.

Intuitively, the treatment of non-culprit lesions during primary PCI is beneficial, as the reperfusion success should be more profound and subsequent cardiac events might be avoided. However, large registries have reported conflicting outcomes and generally the opposite [6-12]. In some of these registries, the culprit-only strategy has even been associated with a lower mortality than complete multi-vessel revascularization. This underscored the risk of an ad-hoc multi-vessel stenting, probably explained by a prothrombotic and inflammatory milieu, additional contrast load and damaged left ventricular function in the acute phase. This promoted the assumption of an increased hazard from multi-vessel PCI in acute patients. Consequently, practice guidelines recommended to confine primary PCI to the infarct-related artery only, and to potentially treat other lesions later on, depending on the evidence of residual myocardial ischemia $[1,2]$.

The culprit-only strategy may also be preferred as coronary stenoses remote from the infarct related artery could be angiographically overestimated in the acute setting, and lesions may regress when coronary spasm resolves. These observations may reflect a heightened vascular tone in infarct- and non-infarct-related arteries, and indicate that non-culprit lesions may not be a valid target in primary PCI, at least in hemodynamically stable patients [13]. For patients in cardiogenic shock, however, pathophysiologic considerations and some observational data support the concept of multi-vessel PCI, though this notion is not yet supported with large randomized trials [14-18].
On the other hand, the disadvantage of the conservative approach is that one relies on symptoms and ischemia tests in patients in whom symptoms were often absent before their STEMI presentation, and who have MVD and/or have an abnormal electrocardiogram. These factors often make non-invasive ischemiadetecting tests less reliable. In addition, complete revascularization may have benefits, which have not yet been adequately investigated. Plaque instability is not limited to the culprit lesion only, ad-hoc treatment of all significant stenosis may reduce infarct size, and-in analogy to the experience from bypass surgery-complete coronary revascularization should result in better long-term prognosis. Furthermore, patients feel more comfortable knowing that residual stenoses have been treated. Nevertheless, the appropriateness of additional PCI/stent procedures of apparently significant (asymptomatic) non-culprit lesions is highly debatable with only limited evidence (Table 1).

Common sense has changed to some extent with the recent publication of randomized

Table 1 Pros and Cons of complete revascularization in STEMI patients with MVD

\begin{tabular}{ll}
\hline $\begin{array}{l}\text { Pro complete } \\
\text { revascularization }\end{array}$ & $\begin{array}{l}\text { Contra complete } \\
\text { revascularization }\end{array}$ \\
\hline $\begin{array}{l}\text { Multiple vulnerable } \\
\text { plaques }\end{array}$ & $\begin{array}{c}\text { Overestimation of lesion } \\
\text { severity }\end{array}$ \\
$\begin{array}{l}\text { Improved myocardial } \\
\text { recovery }\end{array}$ & $\begin{array}{c}\text { More contrast-induced } \\
\text { kidney injury }\end{array}$ \\
Less subsequent & Longer duration of primary \\
revascularizations & PCI \\
Higher patient comfort & Higher risk of stent \\
& thrombosis \\
\hline $\begin{array}{l}M V D \text { multi-vessel disease, } \\
\text { intervention, } \text { PCI percutaneous coronary }\end{array}$ \\
infarction
\end{tabular}


trials. The preventive angioplasty in acute myocardial infarction (PRAMI [ISRCTN registry \#ISRCTN73028481]) trial enrolled 465 patients with acute STEMI and more than $50 \%$ stenoses in non-infarct-related arteries [19]. After completion of the infarct-artery PCI, patients were randomly assigned to either preventive PCI (234 patients) or no preventive PCI (231 patients). Subsequent PCI for angina was recommended only for refractory angina with objective evidence of ischemia. The primary outcome was a composite of death from cardiac causes, nonfatal myocardial infarction (MI), or refractory angina. The study was prematurely stopped based on a highly significant between group differences in the primary outcome favoring preventive PCI. In the group of preventive PCI of non-culprit arteries the combined rate of cardiac death, nonfatal MI, or refractory angina was reduced by $65 \%$, an absolute risk reduction of $14 \%$ points over 23 months. The effect was similar in magnitude and remained highly significant when the analysis was limited to cardiac death and nonfatal MI.

The findings of the PRAMI trial were supported by the Complete versus Culprit Lesion only Primary PCI (CvLPRIT [ISRCTN registry \#ISRCTN70913605]) trial, which randomized 297 STEMI patients with MVD to receive infarct-only or complete revascularization [20]. In the latter group, treatment of any significantly stenosed noninfarct-related arteries was ideally performed within the same procedure, but at least during the index hospitalization. Calculated by time to first event, the 12-month risk of major adverse cardiac events (primary endpoint; total mortality, recurrent MI, heart failure, and ischemia-driven revascularization) was $55 \%$ lower in the complete revascularization group $(21.2 \%$ vs. $10.0 \%, p<0.009)$. Though the numbers were small, complete revascularization numerically affected all single components of the primary endpoint, and the difference was not only driven by more repeat revascularizations in the infarct-only group. Further randomized trials are ongoing, and the largest study (COMPLETE, ClinicaTrials.gov \#NCT01740479) compares complete revascularization (acute or staged) versus culprit-only with conservative strategy, and is currently enrolling 3900 patients in the USA and Canada.

In aggregate, we are currently facing the dilemma that large observational data document higher mortality and small randomized studies indicate a benefit with complete revascularization. At this point, the new European Society of Cardiology guideline for management of patients presenting with STEMI still recommends that primary PCI should be limited to the culprit vessel with the exception of cardiogenic shock and persistent ischemia after PCI of the supposed culprit lesion. Immediate revascularization of a significant non-culprit lesion in selected patients has received no more than a class IIb recommendation [21].

In patients with stable coronary artery disease, fractional flow reserve (FFR) has become the standard of care for defining flowlimiting coronary lesions requiring mechanical revascularisation in the catheterization laboratory [1]. It is presently under investigation, whether FFR will help us to resolve the dilemma of non-culprit lesions in patients undergoing primary PCI.

\section{FFR IN STABLE CORONARY ARTERY DISEASE}

FFR is the present standard for invasive quantification of the functional severity of 
coronary lesions [22]. Intravascular imaging techniques provide useful information such as lumen area or composition of the vessel wall, but FFR is able to supply a physiological assessment of a coronary stenosis. FFR is unique as it takes the contribution of collaterals into account and relates the severity of the stenosis to the mass of the myocardial tissue to be perfused. FFR also has a high spatial resolution, which is particularly helpful in diffusely diseased arteries and/or sequential stenoses. Stenoses with FFR below 0.75 mostly induce myocardial ischemia, whereas stenoses with FFR over 0.80 are hardly associated with exercise-induced ischemia. Despite a gray zone for FFR (between 0.75 and 0.80), the 0.80 criterion has gained widespread acceptance and its clinical role has been validated in outcome studies. FFR is established in stable patients undergoing coronary angiography without prior non-invasive functional testing in the presence of borderline lesions and in patients with MVD undergoing PCI [22]. The concept of avoiding unnecessary treatment of lesions that are not hemodynamically relevant was demonstrated in the DEFER (ClinicaTrials.gov \#NCT01717573) and FFR vs. Angiography for Multivessel Evaluation (FAME [ClinicalTrials.gov \#NCT00267774) trials [23, 24]. More recently, the FAME II (ClinicalTrials.gov \#NCT01132495) trial demonstrated that, in patients with stable coronary artery disease, FFR-guided PCI using drug eluting stents resulted in less need for urgent revascularization compared to medical treatment [25].

The concept of FFR-guided PCI in stable coronary artery disease is based on simple mathematical assumptions, which build the rational to conservative or interventional management of coronary lesions: the intrinsic risk of an ischemic stenosis for death or MI is at least $5 \%$ per stenosis per year. The intrinsic risk of the non-ischemic lesions, in contrast, is $1 \%$ per year or less. By stenting a stenosis (whether functionally significant or not), the risk of death or MI is approximately $3 \%$ per year [22]. It is obvious that numerous factors such as stent technologies, pharmacotherapy or patient characteristics can change that risk benefit equation.

\section{FRACTIONAL FLOW RESERVE IN THE SETTING OF ACUTE MI}

The presence of viable microvasculature is obligatory for a maximal hyperemia, which is integral to an FFR measurement. In the infarct zone, however, a certain degree of microvascular dysfunction can be expected. Therefore, in the setting of an acute MI, even flow limiting lesions in the culprit vessel may have false negative FFR values due to myocardial stunning and acute microvascular dysfunction. Due to these considerations, acute FFR measurements are not valid in the infarctrelated artery [22].

A group of patients that could gain benefit from FFR measurements to identify the culprit lesion are patients with MI secondary to ischemic imbalance. Patients with severe anemia, sepsis, tachycardia, respiratory failure, etc. do not necessary have a thrombus formation, plaque rupture or other morphologic changes, detectable with angiography or additional imaging. But they may have flow limiting lesions, which cause myocardial damage due to long-lasting ischemia [26]. Such lesions could be easily identified using FFR.

The possibly best application of FFR in STEMI patients, however, is the functional assessment of non-culprit lesions in patients 
with otherwise clear culprit vessels. Ntalianis et al. reported the reliability of FFR measurements of non-culprit lesions in acute MI [27]. In their study, FFR measurements were performed immediately after treatment of the culprit vessel in 101 patients and 112 nonculprit lesions and were repeated with the same position of the pressure-wire after 35 days. The authors reported a very good reproducibility of FFR. Only in two patients the FFR-value
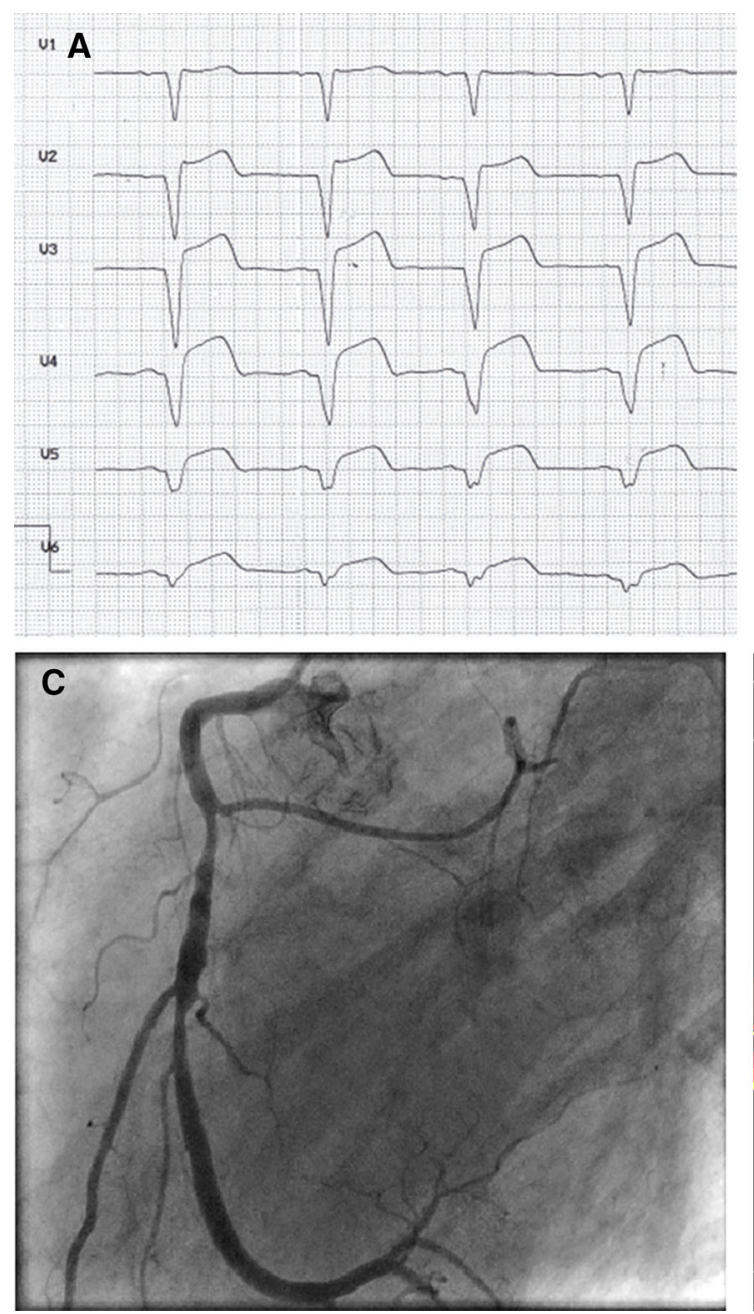

Fig. 1 A 59 year old patient with acute anterior STsegment elevation myocardial infarction and multivessel coronary artery disease. a Electrocardiogramat admission with anterior ST elevation. b Culprit lesion in the left anterior descending. c An angiographically at least intermediate lesion of the right coronary artery (RCA). changed from $>0.8$ during primary PCI to $<0.75$ at follow-up, while all other patients had no meaningful changes of their FFR-values [27].

The main disadvantage of FFR measurement at the time of primary PCI is the need for additional instruments, radiation, and contrast, and-even if performed by experienced operators-it will prolong the procedure. The need for achieving maximal hyperemia usually
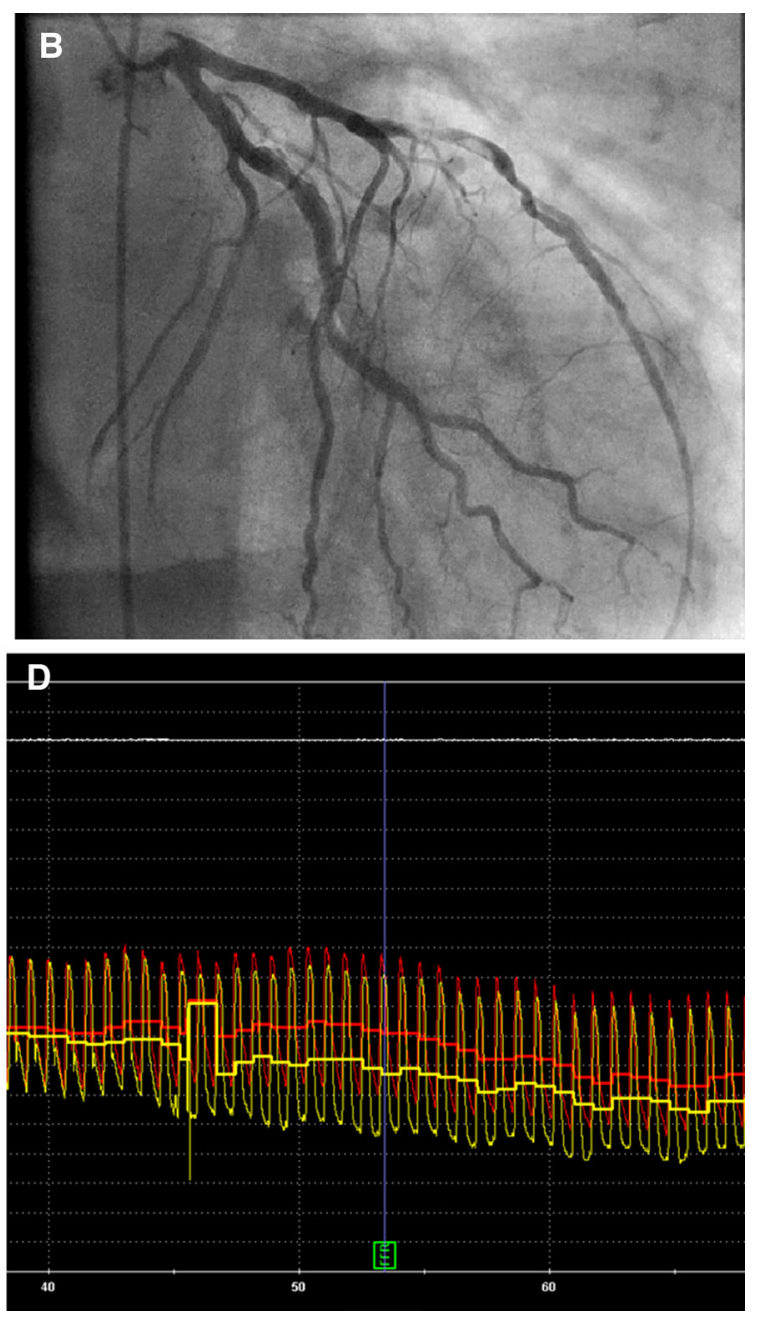

d Fractional flow reserve of the RCA was 0.83 , and the decision about the non-culprit vessel based on functional assessment was possible during the primary intervention. However, the rationale of this strategy is being tested in a current trial 
with adenosine could be problematic in patients with asthma or a preexisting high degree atrioventricular-block (HAVB). However, the incidence of HAVB in patients with acute coronary syndrome is low. Singh et al. reported an incidence of HAVB of $2.9 \%$ at any point during the index hospitalization for an acute coronary syndrome [28]. Gang et al. reported an overall incidence of $3.2 \%$ in patients with acute MI, but culprit lesions in the right coronary artery were associated with a significantly higher rate (7\%) [29]. Moreover, the presence of cardiogenic shock, severe hypotension or bradycardia may limit the use of adenosine-derived FFR. The recently introduced instant wave-free ratio and the basal stenosis resistance are modalities for functional assessment of coronary artery stenosis that are adenosine-independent [30, 31 ], and these methods may have a future in patients with contraindications for adenosine. Nevertheless, the very short half-life of adenosine makes measurements possible without complications in the majority of these cases. In fact, many trials report no or very low rates of FFR-related complications, even in acute coronary syndromes [32-34].

Although current data have confirmed the reliability and safety of FFR measurements in the setting of MI, the relevance of the obtained information about functional severity of coronary lesions is currently being assessed. The COMPARE ACUTE (ClinicalTrials.gov \#NCT01399736) trial is an ongoing prospective, randomized trial carried out at multiple sites across Europe and Asia [35]. Patients are randomly allocated to receive either an FFR-guided multi-vessel PCI vs. culprit-only PCI in the setting of STEMI. The primary study endpoint is a composite of death, MI, any revascularization, or cerebral accident at 12 months. FFR measurements are performed directly after completion of primary PCI in all non-infarct-related arteries with a stenosis of $\geq 50 \%$. Figure 1 demonstrates a case from the COMPARE ACUTE cohort with an anterior STEMI and multivessel disease. Positive FFR measurements are defined as $\leq 0.80$ under maximal hyperemia. Preliminary FFR data of 613 patients show that $56.5 \%$ of the FFR measurements were negative and only $43.5 \%$ were positive [35]. It is worth to mention here that the rate of positive FFR measurements in the FFR-guided group of the FAME trial was $63 \%$, which underscores the contention that lesions are overestimated by conventional methods in acute patients.

\section{ACKNOWLEDGMENTS}

All named authors meet the International Committee of Medical Journal Editors (ICMJE) criteria for authorship for this manuscript, take responsibility for the integrity of the work as a whole, article and have given final approval for the version to be published. No funding or sponsorship was received for this study or publication of this article.

Conflict of interest. M. Abdel-Wahab reports being a proctor for Boston Scientific. Dmitriy S. Sulimov and Gert Richardt do not report any conflict of interest in relation to the contents of this manuscript.

Compliance with ethics guidelines. The authors are investigators of the COMPARE ACUTE trial, but the analyses provided in this article are based on previously conducted studies, and do not involve any new studies of human or animal subjects performed by any of the authors. 
Open Access. This article is distributed under the terms of the Creative Commons Attribution Noncommercial License which permits any noncommercial use, distribution, and reproduction in any medium, provided the original author(s) and the source are credited.

\section{REFERENCES}

1. Steg PG, James SK, Atar D, et al. ESC guidelines for the management of acute myocardial infarction in patients presenting with ST-segment elevation. Eur Heart J. 2012;33:2569-619.

2. O'Gara PT, Kushner FG, Ascheim DD, et al. ACCF/ AHA guideline for the management of ST-elevation myocardial infarction: a report of the American College of Cardiology Foundation/American Heart Association Task Force on Practice Guidelines. J Am Coll Cardiol. 2013;2013(61):e78-140.

3. Muller DW, Topol EJ, Ellis SG, et al. Thrombolysis and Angioplasty in Myocardial Infarction (TAMI) Study Group. Multivessel coronary artery disease: a key predictor of short-term prognosis after reperfusion therapy for acute myocardial infarction. Am Heart J. 1991;121:1042-9.

4. Jaski BE, Cohen JD, Trausch J, et al. Outcome of urgent percutaneous transluminal coronary angioplasty in acute myocardial infarction: comparison of single-vessel versus multivessel coronary artery disease. Am Heart J. 1992;124:1427-33.

5. Sorajja P, Gersh BJ, Cox DA, et al. Impact of multivessel disease on reperfusion success and clinical outcomes in patients undergoing primary percutaneous coronary intervention for acute myocardial infarction. Eur Heart J. 2007;28:1709-16.

6. Vlaar PJ, Mahmoud KD, Holmes DR Jr, et al. Culprit vessel only versus multivessel and staged percutaneous coronary intervention for multivessel disease in patients presenting with STsegment elevation myocardial infarction: a pairwise and network meta-analysis. J Am Coll Cardiol. 2011;58:692-703.

7. Bainey KR, Mehta SR, Lai T, Welsh RC. Complete vs culprit-only revascularization for patients with multivessel disease undergoing primary percutaneous coronary intervention for STsegment elevation myocardial infarction: a systematic review and meta-analysis. Am Heart J. 2014;167:1-14.
8. Bagai A, Thavendiranathan P, Sharieff W, Al Lawati HA, Cheema AN. Non-infarct-related artery revascularization during primary percutaneous coronary intervention for ST-segment elevation myocardial infarction: a systematic review and meta-analysis. Am Heart J. 2013;166:684-93.

9. Kornowski R, Mehran R, Dangas G, et al. Prognostic impact of staged vs. "one-time" multivessel percutaneous intervention in acute myocardial infarction: analysis from the HORIZONS-AMI (harmonizing outcomes with revascularization and stents in acute myocardial infarction) trial. J Am Coll Cardiol. 2011;58:704-11.

10. Hannan EL, Samadashvili Z, Walford G, et al. Culprit vessel percutaneous coronary intervention vs. multivessel and staged percutaneous coronary intervention for ST-segment elevation myocardial infarction patients with multivessel disease. JACC Cardiovasc Interv. 2010;3:22-31.

11. Toma M, Buller CE, Westerhout CM, et al. Nonculprit coronary artery percutaneous coronary intervention during acute ST-segment elevation myocardial infarction: insights from the APEXAMI trial. Eur Heart J. 2010;31:1701-7.

12. Iqbal MB, Ilsley $\mathrm{C}$, Kabir $\mathrm{T}$, et al. Culprit vessel versus multivessel intervention at the time of primary percutaneous coronary intervention in patients with ST-segment-elevation myocardial infarction and multivessel disease: real-world analysis of 3,984 patients in London. Circ Cardiovasc Qual Outcomes. 2014;7:936-43.

13. Hanratty CG, Koyama Y, Rasmussen HH, Nelson GI, Hansen PS, Ward MR. Exaggeration of nonculprit stenosis severity during acute myocardial infarction: implications for immediate multivessel revascularization. J Am Coll Cardiol. 2002;40:911-6.

14. Mylotte D, Morice M-C, Eltchaninoff $\mathrm{H}$, et al. Primary percutaneous coronary intervention in patients with acute myocardial infarction, resuscitated cardiac arrest, and cardiogenic shock: the role of primary multivessel revascularization. J Am Coll Cardiol Intv. 2013;6(2):115-25.

15. Zeymer U, Werdan K, Schuler G, Neumann F, Thiele $\mathrm{H}$. Immediate multivessel intervention in patients with multivessel disease undergoing primary PCI for cardiogenic shock: results of the prospective IABP-SHOCK Trial. J Am Coll Cardiol. 2013;61(10_S). doi:10.1016/S0735-1097(13)601023.

16. Zeymer $\mathrm{U}$, Hochadel $\mathrm{M}$, Thiele $\mathrm{H}$, et al. Immediate multivessel percutaneous coronary intervention versus culprit lesion intervention in patients with acute myocardial infarction complicated by 
cardiogenic shock: results of the ALKK-PCI registry. EuroIntervention. 2014. doi:10.4244/EIJY14M08_ 04.

17. Bauer T, Zeymer U, Hochadel $M$, et al. Use and outcomes of multivessel percutaneous coronary intervention in patients with acute myocardial infarction complicated by cardiogenic shock (from the EHS-PCI Registry). Am J Cardiol. 2012;109:941-6.

18. Hussain F, Philipp RK, Ducas RA, et al. The ability to achieve complete revascularization is associated with improved in-hospital survival in cardiogenic shock due to myocardial infarction: Manitoba cardiogenic SHOCK Registry investigators. Catheter Cardiovasc Interv. 2011;78:540-8.

19. Wald DS, Morris JK, Wald NJ, et al. Randomized trial of preventive angioplasty in myocardial infarction. N Engl J Med. 2013;369:1115-1.

20. Gershlick AH, Khan JN, Kelly DJ, et al. Randomized trial of complete versus lesion-only revascularization in patients undergoing primary percutaneous coronary intervention for STEMI and multivessel disease: the CvLPRIT trial. J Am Coll Cardiol. 2015;65(10):963-72.

21. Windecker S, Kolh P, Alfonso F, et al. 2014 ESC/ EACTS guidelines on myocardial revascularization: the Task Force on Myocardial Revascularization of the European Society of Cardiology (ESC) and the European Association for Cardio-Thoracic Surgery (EACTS) Developed with the special contribution of the European Association of Percutaneous Cardiovascular Interventions (EAPCI). Eur Heart J. 2014;35:2541-619.

22. Pijls NH, Sels JW. Functional measurement of coronary stenosis. J Am Coll Cardiol. 2012;59:1045-57.

23. Pijls NJ, van Schaardenburgh P, Manoharan G, et al. Percutaneous coronary intervention of functionally nonsignificant stenosis: 5-year follow-up of the DEFER Study. J Am Coll Cardiol. 2007;49(21):2105-11. doi:10.1016/j.jacc.2007.01. 087.

24. Tonino PA, De Bruyne B, Pijls NHJ, et al. Fractional flow reserve versus angiography for guiding percutaneous coronary intervention. N Engl J Med. 2009;360:213-24.

25. De Bruyne B, Pijls NH, Kalesan B, et al. Fractional flow reserve-guided PCI versus medical therapy in stable coronary disease. N Engl J Med. 2012;367:991-1001.
26. Thygesen K, Alpert JS, Jaffe AS, et al. Third universal definition of myocardial infarction. Eur Heart J. 2012;33:2551-67.

27. Ntalianis A, Sels JW, Davidavicius G, et al. Fractional flow reserve for the assessment of nonculprit coronary artery stenosis in patients with acute myocardial infarction. JACC Cardiovasc Interv. 2010;3:1274-81.

28. Singh SM, FitzGerald G, Yan AT, et al. High-grade atrioventricular block in acute coronary syndromes: insights from the Global Registry of Acute Coronary Events. Eur Heart J. 2015;36(16):976-83. doi:10. 1093/eurheartj/ehu357.

29. Gang UJ, Hvelplund A, Pedersen S, et al. Highdegree atrioventricular block complicating STsegment elevation myocardial infarction in the era of primary percutaneous coronary intervention. Europace. 2012;14(11):1639-45.

30. Sen S, Asrress KN, Nijjer S, et al. Diagnostic classification of the instantaneous wave-free ratio is equivalent to fractional flow reserve and is not improved with adenosine administration: results of CLARIFY (Classification Accuracy of Pressure-Only Ratios Against Indices Using Flow Study). J Am Coll Cardiol. 2013;61:1409-20.

31. Sen S, Escaned J, Mailk IS, et al. Development and validation of a new adenosine-independent index of stenosis severity from coronary wave-intensity analysis: results of the ADVISE (ADenosine Vasodilator Independent Stenosis Evaluation Study). J Am Coll Cardiol. 2012;59:1392-402.

32. Sels JW, Tonino PA, Siebert U, et al. Fractional flow reserve in unstable angina and non-ST-segment elevation myocardial infarction experience from the FAME (Fractional flow reserve versus Angiography for Multivessel Evaluation) study. JACC Cardiovasc Interv. 2011;4(11):1183-9.

33. López-Palop R, Carrillo P, Frutos A, et al. Usefulness of the fractional flow reserve derived by intracoronary pressure wire for evaluating angiographically intermediate lesions in acute coronary syndrome. Rev Esp Cardiol. 2010;63(6):686-94.

34. Kim HL, Koo BK, Nam CW, et al. Clinical and physiological outcomes of fractional flow reserveguided percutaneous coronary intervention in patients with serial stenoses within one coronary artery. JACC Cardiovasc Interv. 2012;5(10):1013-8.

35. Smits PC, Vlachojannis GJ, Lunde K, et al. TCT-328 FFR-guided complete revascularization during primary PCI: preliminary data from the COMPARE ACUTE trial. J Am Coll Cardiol. 2014;64(11_S). 